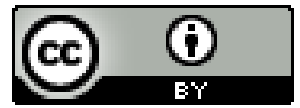

\title{
AS NARRATIVAS DE MULHERES NEGRAS SOBRE ADOECIMENTO APÓS O PROCESSO MIGRATÓRIO: A EXPERIÊNCIA DE MORADORAS DO MUNICÍPIO DE SÃO PAULO
}

\author{
Maria Cecilia Leite de Moraes ${ }^{1}$ \\ Maria Natália Pereira Ramos ${ }^{2}$ \\ Climene Laura de Camargo ${ }^{3}$
}

\begin{abstract}
Resumo: A genderização ampliou os estudos sobre os deslocamentos humanos. A mulher negra participa do processo, saindo de países com graves problemas sociais e, se incorporando a novas comunidades. $\mathrm{O}$ objetivo do estudo foi conhecer a existência de adoecimentos pós-migratórios, a partir de 33 mulheres do grupo. Foi desenvolvida uma pesquisa quali-quantitativa, transversal, realizada entre outubro de 2017 e agosto de 2018, no município de São Paulo- Brasil. Os dados foram obtidos por meio de instrumental constituído por um questionário semiestruturado e uma entrevista. Os dados foram analisados por meio da técnica do Discurso do Sujeito Coletivo. Os relatos destacaram que $51,2 \%$ das mulheres não adoeceram, e 45,4\% adoeceram sendo que $27,2 \%$ declararam problemas emocionais. Constata-se a necessidade de padrões para acolhimento e, concepção de políticas à saúde e inclusão do grupo.
\end{abstract}

Palavras-Chave: Acolhimento; Assistência Integral à Saúde da Mulher; Imigração; País Receptor de Imigrantes; População Negra.

\footnotetext{
${ }^{1}$ Doutora em Saúde Pública pela Faculdade de Saúde Pública da Universidades de São Paulo, Pós Doutora pela Escola de Enfermagem da Universidade Federal Da Bahia, Pesquisadora do Grupo de Estudos da Criança e do adolescente - CRESCER da EE/UFBA. https://orcid.org/0000-0002-8717-6513. E-mail: leimo7@hotmail.com

${ }^{2}$ Doutora e Pós-Doutora em Psicologia Clínica e Intercultural pela Universidade René Descartes, Paris V, Sorbonne. Professora Associada da Universidade Aberta, Lisboa. Coordenadora Científica do Centro de Estudos das Migrações e das Relações Interculturais / CEMRI / UAB / FCT. https://orcid.org/0000-00028448-1846. E-mail: natalia@uab.pt

${ }^{3}$ Doutora em Saúde Pública pela Faculdade de Saúde Pública da Universidade de São Paulo, Pós Doutora pela Université René Descartes, Paris V, Sorbonne; Professora da Escola de Enfermagem da Universidade Federal da Bahia, Coordenadora e Pesquisadora do Grupo de Estudos da Criança e do adolescente CRESCER da EE/UFBA. https://orcid.org/0000-0002-4880-3916. E-mail: climenecamargo@ hotmail.com
} 


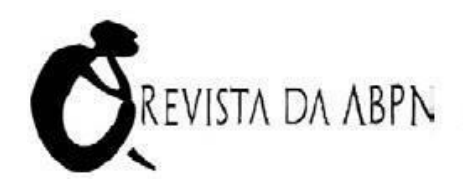

$\triangle \nabla \Delta \nabla \Delta \nabla \Delta \nabla \Delta \nabla \Delta \nabla \Delta \nabla \Delta \nabla \Delta \nabla \Delta \nabla \Delta \nabla \Delta \nabla \Delta \nabla \Delta \nabla \Delta \nabla \Delta \nabla \Delta \nabla \Delta \nabla \nabla$

\author{
THE NARRATIVES OF BLACK WOMEN ABOUT ADOANCING \\ AFTER THE IMMIGRATORY PROCESS: THE EXPERIENCE OF \\ RESIDENTES IN THE MUNICIPALITTY OF SÃO PAULO
}

\begin{abstract}
Genderization has expanded studies on human displacement. Black women participate in the process, leaving countries with serious social problems and joining new communities. The objective of the study was to know the existence of post-migratory illnesses, from 33 women in the group. A cross-sectional quali-quantitative research was carried out between October 2017 and August 2018, in the city of São Paulo-Brazil. Data were obtained using instruments consisting of a semi-structured questionnaire and an interview. The data were analyzed using the Collective Subject Discourse technique. The reports highlighted that $51.2 \%$ of women did not fall ill, and $45.4 \%$ fell ill, with $27.2 \%$ declaring emotional problems. There is a need for standards for reception and design of health policies and inclusion of the group.
\end{abstract}

Keywords: Welcoming; Assistance Health Care for Women; Immigration; Immigrant Receiving Country; Black Population.

\title{
LAS NARRATIVAS DE LAS MUJERES NEGRAS ACERCA DEL AVANCE DESPUÉS DEL PROCESO INMIGRATORIO: LA EXPERIENCIA DE LOS RESIDENTES EN EL MUNICIPIO DE SÃO PAULO
}

Resumen: El género ha ampliado los estudios sobre desplazamiento humano. Las mujeres negras participan en el proceso, dejando a los países con graves problemas sociales y uniéndose a nuevas comunidades. El objetivo del estudio fue conocer la existencia de enfermedades post-migratorias, de 33 mujeres en el grupo. Se realizó una investigación transversal cualitativa y cuantitativa entre octubre de 2017 y agosto de 2018 en la ciudad de São Paulo-Brasil. Los datos se obtuvieron utilizando instrumentos que consisten en un cuestionario semiestructurado y una entrevista. Los datos se analizaron utilizando la técnica de Discurso del sujeto colectivo. Los informes destacaron que el $51.2 \%$ de las mujeres no enfermaron, y el $45.4 \%$ enfermó, y el $27.2 \%$ declaró problemas emocionales. Se necesitan normas para la recepción y el diseño de políticas de salud y la inclusión del grupo.

Palabras-clave: Anfitrión; Asistencia Integral a la Salud de la Mujer; Inmigración; País Receptor de Inmigrantes; Población Negra.

\section{LES NARRATIFS DES FEMMES NOIRES SUR L'ADAPTATION APRÈS LE PROCESSUS D'IMMIGRATION: L'EXPERIÉNCE DES RÉSIDENTS DE LA MUNICIPALITÉ DE SÃO PAULO}

Résumé: Le genre a élargi les études sur le déplacement humain. Les femmes noires participent au processus, laissant des pays avec de graves problèmes sociaux et rejoignant de nouvelles communautés. L'objectif de l'étude était de connaître l'existence de maladies post-migratoires, auprès de 33 femmes du groupe. Une recherche qualitative et quantitative transversale a été réalisée entre octobre 2017 et août 2018, dans la ville de São Paulo-Brésil. Les données ont été obtenues à l'aide d'instruments consistant en un questionnaire semi-structuré et une interview. Les données ont été analysées à l'aide de la technique du discours sujet collectif. Les rapports ont souligné que 51,2\% des femmes 
ne sont pas tombées malades et 45,4\% sont tombées malades, 27,2\% déclarant des problèmes émotionnels. Il y a un besoin de normes pour l'accueil et la conception des politiques de santé et l'inclusion du groupe.

Mots-clés: Bienvenue; Assistance Globale à la Santé des Femmes; Immigration; Pays D'accueil des Immigrants; Population Noire.

\section{INTRODUÇÃO}

A mobilidade humana é um tema de grande relevância na contemporaneidade (RAMOS, 2017), pois implica em alterações no cenário local, nacional e mundial. O Brasil, historicamente, à exceção dos indígenas oriundos da terra, é um país formado por imigrantes (LIMA; SILVA, 2017). Imigrações que se potencializaram no período pósabolição, quando foram recebidos, contingentes significativos de pessoas consideradas qualificadas para o trabalho, aglutinando o projeto de branqueamento da população brasileira.

A história relata que povos dos mais diversos e longínquos lugares da Europa (Itália, Inglaterra) e Ásia (Japão) chegaram para construir uma nova vida e contribuir para a composição de uma nação forte, sólida e próspera (GRANADA et al., 2017). É com este pano de fundo que se corporifica o racismo e a discriminação no país (SANTOS; ROCHA, 2016). A realidade brasileira mostra, de maneira contundente, uma sociedade opressiva edificada sobre preconceitos latentes em relação aos grupos não hegemônicos, isto é, os indivíduos não brancos (BASTOS, 2016).

O aumento da participação feminina nas imigrações, conhecido como genderização ou feminização migratória (RAMOS, 2012; RAMOS, 2014 e SILVA; NEVES, 2016), ampliou os estudos sobre os deslocamentos humanos (NEVES et al., 2016; RAMOS; FRANKEN, 2018 e MOURA; RAMOS, 2018) e transformou a agenda científica - já que as mulheres assumiram o protagonismo em tal processo. Em 2010, representavam 50\% das migrações mundiais (TOPA; NEVES; NOGUEIRA, 2013) nos dias presentes, a feminização alcançou números ainda maiores (RAMOS; FRANKEN, 2018; BERTOLDO, 2018).

Cabe esclarecer quatro termos empregados nos estudos de movimentação humana: migrante, emigrante, imigrante e refugiado. O migrante é o indivíduo que se movimenta através de uma fronteira bem definida (CIERCO, 2017). O emigrante sai de 
sua fronteira de origem para outro país; o imigrante entra em um novo país para viver ou trabalhar (GUIA; PEDROSO, 2015). O refugiado é alguém que foi obrigado a atravessar fronteiras internacionais em virtude de perseguições e ameaças à vida geradas por questões de raça, religião, posição e/ou opinião política (CASTIGLIONE, 2018).

Os indivíduos movimentam-se procurando transformação e mudança (VASCONCELOS; SANTOS, 2017). Em parte dos casos, esse tipo de mudança ocorre como uma resposta às circunstâncias difíceis da vida, como por exemplo, problemas sociais (MAXIMILIANO, 2018). São situações que tornam, muitas vezes, a escolha pelo país incerta e duvidosa, realizada em função de necessidade e calor do momento. Frequentemente, são viagens sem ou com pouco planejamento, decididas diante do medo e do desespero, em que muito ou tudo é deixado para trás. A mobilidade humana produz impacto na vida, saúde e bem-estar de milhões de pessoas (RAMOS, 2012; RAMOS, 2017; PACHÍ, 2017) e resulta em fissuras afetivas, culturais, familiares, sociais, de referências geográficas e linguísticas.

Ao mesmo tempo, reconhece-se que as diferenças e dificuldades podem ser superadas por cooperação e solidariedade (RAMOS, 2014; RAMOS; MONTEIRO; VIEIRA, 2017). É possível a preservação identitária e a coexistência pacífica e respeitosa entre imigrantes e nacionais. O compartilhamento dos saberes é uma das virtudes da movimentação humana. Igualmente, as imigrações ressignificam famílias, identidades, novas relações e cooperações entre os sujeitos (CARLEIAL, 2016).

No âmbito internacional, a migração é observada como uma importante questão de saúde pública, dado que os deslocamentos podem contribuir na vulnerabilidade dos indivíduos e grupos, no que diz respeito às exigências de aculturação e aos danos à saúde (RAMOS, 2014; RAMOS, 2017; ROCHA et al., 2012). Os deslocamentos podem ser considerados fatores de risco à saúde mental em razão de conflitos psicológicos decorrentes do processo (RAMOS, 2004; NETO, 2008; TOPA; NEVES; NOGUEIRA, 2010).

Estudo ressalta as consequências da imigração em relação à mulher descritas a partir de três eixos temáticos: migração seletiva, efeito negativo da imigração na saúde e aculturação (IM; YANK, 2006).

A migração seletiva acontece pela escolha. Neste grupo encontram-se mulheres saudáveis e resilientes que buscam oportunidades de desenvolvimento pessoal e social. A vivência migratória é vista como um fator de proteção à saúde. 
Os efeitos negativos da imigração à saúde (RAMOS, 2004; IM; YANK, 2006) são as respostas estressoras à mobilidade que propiciam uma conjuntura de riscos. As mulheres que vivenciam este processo apresentam maior prevalência de doenças físicas e mentais (COUTINHO; RODRIGUES; RAMOS, 2012). Os quadros apontados podem ser relativos às condições de vida e doenças endêmicas do país de origem, assim como, ao contexto psicossocial e político da migração.

A aculturação é o processo de adaptação vivenciado pelo migrante, gerado por novos conhecimentos, competências, padrões, regras e linguagem (RAMOS, 2012; REIS; RAMOS, 2010). Resulta do contato prolongado e direto entre indivíduos de culturas diferentes e ocorre pela incorporação dos padrões do grupo dominante (ANTÓNIO et al.,2011; GOULÃO et al., 2015). A aculturação torna-se potente nos primeiros anos de imigração e é sinalizada por períodos de longo sofrimento, fato que pode impactar na saúde do sujeito (REIS; RAMOS, 2010; COUTINHO; RODRIGUES; RAMOS, 2012).

Pesquisas pontuam que a relação entre imigração e presença de problemas de saúde mental é complexa, multidimensional e contextual (RAMOS, 2004; COUTINHO; RODRIGUES; RAMOS, 2012). Ademais, todos os aspectos descritos guardam uma forte relação com a tríade pessoa imigrante, país de origem e país recebedor. O indivíduo se reconstitui das inúmeras ranhuras impostas pela imigração criando, a partir dos novos contextos e mudanças, um novo tecido para a vida.

Apesar do vigor dos estudos migratórios nos últimos anos, são poucos os escritos que abordam a temática a partir de uma perspectiva étnico-racial. No momento atual, reconhece-se a importância das pesquisas migratórias centradas em questões interculturais (RAMOS, 2014; RAMOS, 2017). Caracterizar e respeitar as diferenças são pontos relevantes para a inserção do imigrante à nova conjuntura (ANTÓNIO et al., 2011).

As mulheres negras que imigram para o Brasil, habitualmente afluem de países subdesenvolvidos como Angola, Congo, Senegal, Nigéria e Haiti. São lugares que se encontram em graves problemas sociopolíticos que fragilizam os indivíduos e o grupo (GOULÃO et al., 2015). Essa situação contribui para que as imigrantes cheguem como refugiadas ou sem documentação (PADILLA, 2013).

Além disso, no Brasil, as mulheres negras nativas destacam-se como a camada mais baixa na divisão social de classes (PEREIRA, 2019; LACERDA et al., 2012), o que 
concorre para a má qualidade de vida que levam, e as tornam mais susceptíveis aos riscos que impactam nas condições de saúde (GRANADA et al., 2017).

Em face do contexto exposto, pretendeu-se conhecer, a partir da narrativa de mulheres negras imigrantes, sobre a existência de adoecimento após o deslocamento.

\section{PROCEDIMENTOS METODOLÓGICOS}

Para a formulação do artigo foi utilizada uma categoria abordada, a qual reporta sobre adoecimento após a imigração. Tratou-se de um estudo descritivo, quantiqualitativo, com delineamento transversal, sob formato de respostas escritas e narradas

As entrevistas aconteceram em 06 (seis) diferentes locais do município de São Paulo: 04 (quatro) estabelecimentos confessionais (caráter religioso), uma Organização Não Governamental e uma Ocupação de Moradores Sem Teto.

Participaram do estudo 33 mulheres negras (inicialmente reconhecidas como negras pela subjetividade do pesquisador e posteriormente autodeclaradas como tal), imigrantes, com mais de 18 anos de idade, que compreendiam e falavam a língua portuguesa. A seleção foi feita a partir de critérios subjetivos, ou seja, convenientes para o pesquisador (FONTANELLA et al., 2011).

Para aquisição dos dados foi elaborado um roteiro semiestruturado constituído por duas partes: questionário sobre o perfil sociodemográfico das participantes e entrevista relacionada às condições de vida da migrante. As entrevistas foram gravadas para transcrição. As participantes assinaram o Termo de Consentimento Livre e Esclarecido. O estudo foi aprovado pelo Comitê de Ética e Pesquisa da Faculdade de Saúde Pública da Universidade de São Paulo, com o parecer número 2518235. A coleta de dados ocorreu entre os meses de outubro de 2017 e agosto de 2018.

A análise dos dados foi realizada de acordo com a Técnica do Discurso do Sujeito Coletivo (DSC) (LEFEVRE; LEFEVRE, 2006). Trata-se de uma estratégia para a coleta, tabulação e organização de dados qualitativos, fundamentada na Teoria da Representação Social (LEFEVRE; LEFEVRE, 2003). Para atender à técnica, as respostas foram agrupadas de acordo com as ideias centrais (IC). As ideias são os arcabouços das expressões chaves $(\mathrm{ECH})$ narradas pelos respondentes. O procedimento permite encadear as expressões chaves $(\mathrm{ECH})$, somando-as, expressando a coletividade e originando os 
Discursos do Sujeito Coletivo (DSC). Os discursos são escritos na primeira ou terceira pessoa do singular. Tal processo permite que todos os participantes sejam representados.

\section{RESULTADOS E DISCUSSÕES}

As narrativas destacaram que 51,2\% das mulheres não reportaram adoecimento, enquanto $45,4 \%$ mulheres referiram ter ficado doentes. Uma das entrevistadas informou já ter chegado doente. Os dados encontram-se destacados na Tabela 1.

Tabela 1: Número e porcentagem de respostas quanto à existência de adoecimento entre as mulheres negras entrevistadas após a imigração para o Brasil

\begin{tabular}{lll}
\hline \multicolumn{1}{c}{ Categorias } & N & $\%$ \\
A. Não adoeceram & 17 & 51,2 \\
B. Adoeceram & 15 & 45,4 \\
C. Chegou doente & 1 & 3,4 \\
Total & $\mathbf{3 3}$ & $\mathbf{1 0 0 , 0}$
\end{tabular}

Fonte: Mulheres negras imigrantes que participaram do estudo. São Paulo, 2018.

Entre as mulheres que mencionaram a presença de doença, 27,2\% referenciaram doenças emocionais, 9,0\% problemas físicos e emocionais, $6,1 \%$ problemas físicos. Uma das entrevistadas $(3,1 \%)$ não especificou o tipo de doença.

Tabela 2: Número e porcentagem de respostas quanto à tipologia da doença declarada entre as mulheres entrevistadas

\begin{tabular}{lll}
\hline \multicolumn{1}{c}{ Categorias } & N & $\%$ \\
A. Doenças emocionais & 9 & 27,2 \\
B. Problemas físicos e emocionais & 3 & 9,0 \\
C. Problemas físicos & 2 & 6,1 \\
D. Não especificou & 1 & 3,1 \\
\hline Fonte: Mulheres negras imigrantes que participaram do estudo. São Paulo, 2018.
\end{tabular}

Distinguiu-se a heterogeneidade neste grupo de mulheres imigrantes (PADILLA, 2013) e, ademais, foram realçadas as diferentes situações de saúde que estão acopladas ao processo de deslocamento. As narrativas expõem a influência das mudanças e das 
condições de vida sobre o estado de saúde da mulher que se movimenta. A tipologia da migração, ser imigrante ou refugiada, divisa a questão de saúde, aspecto consonante com o descrito pela literatura (GRANADA et al., 2017).

Categoria A: Relataram não ter adoecido

"Minha saúde ficou igual, a mudança não trouxe problemas para mim... Sei que no começo foi difícil, fiquei triste e não posso ficar nervosa, prefiro ficar no meu canto, ser quem eu sou. É só saudades, mas não tenho problema, estou bem de saúde”.

As mulheres que migram podem apresentar um melhor estado de saúde e serem resilientes diante dos novos desafios (TOPA; NEVES; NOGUEIRA, 2013). A literatura destaca que os imigrantes são indivíduos, em geral, saudáveis, observando que muitos se deslocam para trabalhar (PADILLA, 2013). Entretanto, cabe ressaltar que a saúde do imigrante mostra fortes conexões com o processo de adaptação e aculturação (RAMOS, 2004; RAMOS, 2012; RAMOS, 2017; SILVA; LIMA; MOTA, 2019). Admite-se que o processo de imigração, por si só, não é o único fator de risco para o adoecimento dos envolvidos (REIS, 2016). Ainda assim, o depoimento mostra que mesmo se percebendo saudável, a mulher negra imigrante faz referências a dificuldades iniciais e à opção pelo isolamento. Estudo anterior mostra que a imigrante saudável tece redes de reciprocidade entre os pares (CARLEIAL, 2016). O agrupamento entre iguais, a solidariedade e apoio do grupo são facilitadores, porque juntos os indivíduos em situação de mobilidade podem elaborar uma nova maneira de viver e superar dificuldades (OLIVEIRA et al., 2016).

Categoria B: Problemas emocionais

“Tensão... muita tensão. Larguei minha família, meu país, e lá eu estava forte. Eu penso na minha filha, que até agora não sei se está viva, se morreu... Isso dói tanto! Mexeu com minha saúde, meu estômago, meu coração... Estou mal no pensamento e no coração... e esse país faz com que as pessoas adoeçam. O médico falou que eu tinha depressão... deve ser verdade."

O processo migratório acarreta rupturas diversas (OKAMOTO; JUSTO; RESSTEL, 2017) e é processado em um contexto que envolve mudanças jurídicas e afetivas (OLIVEIRA et al., 2016). Fomenta desenlaces familiares, sociais, políticos e culturais que podem desencadear a síndrome do imigrante (MÜHLEN; DEWES; LEITE, 2011). São situações construídas por ausências dolorosas e traumáticas, já que muitas mulheres imigrantes vivenciam a maternidade e cuidados dos filhos em situação de isolamento (RAMOS, 2014; RAMOS, 2017). Outras imigrantes vivenciam a 
transferência dos cuidados dos filhos, condição denominada como maternagem transnacional (CARPENEDO; NARDI, 2017). O resultado deste tipo de experiência pode evoluir para quadros como a depressão. Entre os imigrantes africanos o quadro é conhecido, no ramo da psiquiatria cultural, como black depression (PUSSETTI, 2009). Tal cenário recrudesce, também, em função da discriminação, falta de apoio e problemas de identidade (MOURA; RAMOS, 2018)

Categoria C: Problemas emocionais e físicos

"Você passa por muita coisa. Tudo foi me abalando, refletindo no estômago. Fiquei hospitalizada, comecei a ter pressão alta, mas vou seguir em frente”.

Ao deixar o país de origem, novos sentimentos emergem na vida da imigrante: a nostalgia do que ficou para trás e a insegurança pelo futuro passam a delinear o cotidiano (REIS, 2016; OLIVEIRA et al., 2016). Vivenciam o stress por aculturação, que envolve a solidão, a luta por sobrevivência e o medo de fracasso (REIS, 2016). Concorre, também, a especificidade da condição imigratória: escolha, circunstâncias socioeconômicas, refúgio (GRANADA et al., 2017). As demandas por novas organizações internas, reconfigurações e reelaborações identitárias e de sentidos sociais exigem esforços (GOLIN, ASSUMPÇÃO, 2017) que podem desencadear vários sintomas, perturbações e mal-estar (REIS; RAMOS, 2010). É uma experiência complexa e, muitas vezes, insalubre.

Categoria D: Problemas físicos

"Ficou difícil, tenho enxaqueca... Como lá é muito quente, tenho dor nos ossos".

As narrativas manifestam a existência de problemas de saúde física (OLIVEIRA et al., 2016). Evidencia-se a possibilidade de uma pior condição de saúde; especificamente no que se refere a dores (COUTINHO; OLIVEIRA, 2010). As doenças endêmicas do país de origem, conjuntamente com circunstâncias políticas, sociais e ambientais, que propiciaram a mudança, robustecem a situação de adoecimento (TOPA; NEVES; NOGUEIRA, 2013). Entre as principais queixas distinguem-se: fadiga, problemas osteomusculares e cefaleia. Esta última remete à síndrome de Ulisses, que apresenta como um de seus sintomas a enxaqueca originada por tensões do cotidiano e condições de vida (COUTINHO; RODRIGUES; RAMOS, 2012).

Categoria E: Não especificou o problema de saúde

"Minha saúde está ruim..." 
Os esgarçamentos vivenciados pelas migrantes podem gerar quadros de saúde importantes. As disfuncionalidades, as complexidades de adaptação ao novo elucidam questões difíceis de serem descritas (RAMOS, 2017; RAMOS; FRANKEN, 2018). Muitas destas mulheres foram impelidas a reconstruir a vida, fato que as obrigou a desempenhar uma série de novas e estressantes tarefas para a sobrevivência em um clima de muita tensão (RODRIGUES; STREY; ESPINOSA, 2010). Reconhece-se que parte do grupo não possui força e resiliência para vencer todos os obstáculos, aspecto que repercute na saúde integral do indivíduo.

Categoria F: Chegou doente

"Não estava bem. Quando cheguei aqui estava doente... tensão."

Aponta-se que a relação entre as características migratórias, fatos ligados à regularidade ou não do sujeito no novo país e a possibilidade de não adaptação repercutem, vigorosamente, na qualidade de vida e saúde (RAMOS, 2012). Sair do país de origem, abandonar parte da vida e reconhecer os obstáculos que poderão ser encontradas abrem caminho ao adoecimento (WEBER et al., 2019). A vulnerabilidade acompanha a chegada de muitas imigrantes (OLIVEIRA et al., 2016) e a tensão é uma das expressões do quadro de angústia e sofrimento.

\section{CONCLUSÃO}

Um número significativo das mulheres negras entrevistadas manifestou resiliência e superação pós-imigratória no âmbito da saúde. No entanto, mesmo para essas mulheres, destacou-se a opção pelo isolamento no período de adaptação.

Dentre as que relataram adoecimento observou-se, de maneira intensa, a associação entre as características da migração e os efeitos na saúde. Mesmo reconhecendo que não há homogeneidade no que tange a diagnósticos e sintomas, fica claro que os sinais afetivos e emocionais relacionados à separação responderam, em grande medida, pelos incômodos e sofrimentos relatados. A travessia não foi fácil e houve um conjunto de circunstâncias que favoreceu os agravos.

O grupo diferencia-se, de maneira portentosa, de outros grupos migratórios, pois possui marcas específicas relacionadas aos conceitos inscritos em segmentos da sociedade brasileira. Viver com o diferente, com o outro, demanda empatia e alteridade, 
situação que se complica na confluência entre duas categorias que sofrem resistência quanto à adaptação e inclusão de mulheres no Brasil: imigrantes e negras.

Independente tanto do país de origem quanto do receptor, conhecer as novas mobilidades humanas permite não só verificar as modificações constantes na história, dos grupos e dos indivíduos, como visualizar e analisar diásporas que se espalham por um mundo em transformação.

O país que acolhe deve organizar, constantemente, uma agenda política social e de saúde para atender aos imigrantes, em particular às mulheres migrantes. Apesar do Brasil não colocar ressalvas à imigração, acentua-se a relevância da elaboração de políticas públicas de inclusão.

O cenário aponta à exigência de formulação nos padrões metodológicos, estratégicos e políticos para o acolhimento das mulheres negras. Ainda, observa-se a necessidade de ações relacionadas à saúde e inclusão do grupo.

\section{REFERÊNCIAS BIBLIOGRÁFICAS}

BASTOS, Janaína Ribeiro Bueno. O lado branco do racismo: a gênese da identidade branca e a branquitude. Revista da Associação Brasileira de Pesquisadores/as Negros/as (ABPN), [S.1.], v. 8, n. 19, jun. 2016, p. 211-231.

BERTOLDO, Jaqueline. Migração com rosto feminino: múltiplas vulnerabilidades, trabalho doméstico e desafios de políticas e direitos. Revista Katálysis, v. 21, n 2, maio/ago. 2018, p.313323.

CARLEIAL, ADELITA. Redes sociais entre imigrantes. In: XIV ENCONTRO NACIONAL DE ESTUDOS POPULACIONAIS, ABEP, 2004. Anais ... Caxambu-MG: ABEP, 2004. p. 1-11.

CARPENEDO, Manoela; NARDI, Henrique. Maternidade transnacional e produção da subjetividade: as experiências de mulheres imigrantes vivendo em Londres.Cadernos Pagu, 2017, n. 49.

CASTIGLIONE, Débora de Pina. Políticas de fronteiras e saúde de populações refugiadas. Cadernos de Saúde Pública, v.34, n.4, abr. 2018, p. 1-4.

CIERCO, Teresa et al. Esclarecendo conceitos: refugiados, asilados políticos, imigrantes ilegais. In: Fluxos migratórios e refugiados na atualidade. Rio de Janeiro, RJ: Fundação Konrad Adenauer Stiftung, 2017.

COUTINHO, Maria da Penha de Lima; RODRIGUES, Ieda Franken; RAMOS, Natália. Transtornos mentais comuns no contexto migratório internacional. Psico, v. 43 n.3, jul/set. 2012, p. $400-407$. 
COUTINHO, Maria da Penha de Lima; OLIVEIRA, Marcelo Xavier de. Tendências comportamentais frente à saúde de imigrantes brasileiros em Portugal. Psicologia \& Sociedade, v. 22 , n. 3, 2010, p. 548-557.

FONTANELLA, Bruno José Barcellos et al. Amostragem em pesquisas qualitativas: proposta de procedimentos para constatar saturação teórica. Cadernos de Saúde Pública, v. 27, n. 2, fev. 2011, p. 388-94.

GOLIN, Carlo Henrique; ASSUMPÇÃO, Luis Otávio Teles. Educação intercultural em escolas fronteiriças: diálogos sobre fricções culturais na fronteira Brasil-Bolívia. Revista GeoPantanal, v. 12, 2017, p. 27-38.

GOULÃO, Beatriz et al. Prevalência de excesso de peso nos imigrantes brasileiros e africanos residentes em Portugal. Revista Portuguesa de Saúde Pública, v. 33, n. 1, jan.-jun. 2015, p. 2432.

GRANADA, Daniel et al. Discutir saúde e imigração no contexto atual de intensa mobilidade humana. Interface-Comunicação, Saúde, Educação, v. 21, n. 61, 2017, p. 285-296.

GUIA, Maria João; PEDROSO, João. Imigração e crime violento: um olhar a partir de reclusos condenados. Configurações: Revista de Sociologia, v. 16, 2015, p. 25-40.

IM, Eun-Ok; YANG, Kyeongra. Theories on immigrant women's health. Health care for women international, v. 27, n. 8, 2006, p. 666-81.

LACERDA, Roberto dos Santos et al. Fatores que interferem nas disparidades raciais em saúde: impacto do trauma histórico, status socioeconômico e racismo sobre a saúde. Revista da ABPN, v. 4, n. 8, 2012, p, $97-113$.

LEFEVRE, Fernando; LEFEVRE, Ana Maria Cavalcanti. O sujeito coletivo que fala. Interface Comunicação, Saúde, Educação, v 10, n. 20, 2006, p. 517-24.

LEFEVRE, Fernando; LEFEVRE, Ana Maria Cavalcanti. O discurso do sujeito coletivo: um novo enfoque em pesquisa qualitativa; desdobramentos. Porto Alegre: EDUCS, 2003.

LIMA, Sarah Somensi de; SILVA, Leda Maria Messias da. Os imigrantes no Brasil, sua vulnerabilidade e o princípio da igualdade. Revista Brasileira de Políticas Públicas, v. 7, n. 2, 2017, p. 385-403.

MAXIMILIANO, Ana Maria. O âmbito de proteção dos direitos fundamentais sociais aos refugiados venezuelanos no Brasil. Revista eletrônica [do] Tribunal Regional do Trabalho da $9^{a}$ Região, v. 7, n. 68, maio 2018, p. 27-35.

MÜHLEN, Bruna Krimberg von; DEWES, Diego; LEITE, José Carlos de Carvalho. Stress e processo de adaptação em pessoas que mudam de país: uma revisão de literatura. Ciência em movimento, v. 12, n. 24, 2010, p. 59-67.

MOURA, Giovanna Barroca; RAMOS, Natália. Representações sociais de imigrantes latinoamericanos em Espanha sobre imigração e imigrantes. Revista Ambivalências, v. 6, n. 11, 2018, p. 215-241.

NETO, Félix Fernando Monteiro. Estudos de psicologia intercultural - nós e os outros. Lisboa: Fundação Calouste Gülbenkian, 2008. 
NEVES, Ana Sofia Antunes das, et al. Immigrant women in Portugal: a gender analysis. Estudos de Psicologia (Campinas), v. 33, n. 4, out.-dez. 2016, p. 723-733.

OLIVEIRA, Eliany Nazaré et al. Saúde de imigrantes: estudos com brasileiros baseados em evidências. SANARE - Revista de Políticas Públicas, v. 15, n. 1, jan.-jun. 2016, p. 74 - 81.

OKAMOTO, Mary Yoko; JUSTO, José Sterza; RESSTEL, Cizina Célia Fernandes Pereira. Imigração e desamparo nos filhos de dekasseguis. REMHU: Revista Interdisciplinar da Mobilidade Humana, v. 25, n. 50, 2017, p. 203-219.

PACHI, Priscilla. A importância da imigração haitiana na concepção da nova lei municipal (São Paulo) de migração. Travessia - Revista do Migrante, v. 80, 2017, p. 93-104.

PADILLA, Beatriz. Saúde dos imigrantes: multidimensionalidade, desigualdades e acessibilidade em Portugal. REMHU: Revista Interdisciplinar da Mobilidade Humana, v. 21, n. 40, 2013, p. 4968.

PEREIRA, Neusa Maria. Pela mulher negra. In: BIANCA SANTANA (Org.). Vozes insurgentes de mulheres negras: do século XVIII à primeira década do século XXI. Belo Horizonte: Mazza Edições, 2019. p. 64-67.

PUSSETTI, Chiara. Biopolíticas da depressão nos imigrantes africanos. Saúde e sociedade, v. 18, n. 4,2009 , p. 590-608.

RAMOS, Natália. Migração, maternidade e saúde. Repertório: teatro \& dança, v. 15, n. 18, 2012, p. 84-93.

RAMOS, Natália. Gênero, identidade e maternidade em famílias na diáspora. In: ROSA MARIA NEVES SIMAS. (Coord.). A vez e a voz da mulher: relações e migrações. Lisboa: Colibri, 2015. p. 285-299.

RAMOS, Natália; FRANKEN, Ieda. Cidadania e direitos aprisionados de brasileiros imigrantes ilegais na Suíça: implicações na saúde e qualidade de vida. Revista Ambivalências, v. 6, n. 11, 2018, p. 09-34.

RAMOS, Natália. Comunicação em saúde, interculturalidade e competências: desafios para melhor comunicar e intervir na diversidade cultural em saúde. In: MARIA LIGIA RANGEL; NATÁLIA RAMOS. (Orgs.). Comunicação e saúde: perspectivas contemporâneas. Salvador: EDUFBA, 2018. p. 149-172.

RAMOS, Natália. Comunicação em saúde e interculturalidade - perspectivas teóricas, metodológicas e práticas. RECIIS - Revista Eletrónica de Comunicação, Informação e Inovação em Saúde, v. 6, n. 4, 2012, p. 1-11.

RAMOS, Natália; MONTEIRO, Ivete; VIEIRA, Cristina Coimbra. Avós e transmissão intergeracional em famílias hindus migrantes em Portugal. In: LÚCIA VAZ DE CAMPOS MOREIRA; ELAINE PEDREIRA RABINOVICH, MARIA NATÁLIA RAMOS. (Orgs.). Pais, avós e relacionamentos intergeracionais na família contemporânea. Curitiba: CRV, 2017. p. 361380.

RAMOS, Natália. Psicologia clínica e da saúde. Lisboa: Universidade Aberta, 2004.

REIS, Lyria Maria dos; RAMOS, Natália. Comportamentos de saúde e estilos de vida em contexto migratório: um estudo com mulheres e homens brasileiros imigrantes em Portugal. In: 
SEMINÁRIO INTERNACIONAL FAZENDO GÊNERO SANTA CATARINA "DIÁSPORAS, DIVERSIDADES, DESLOCAMENTOS", 9., 2010. Santa Catarina: Universidade Federal de Santa Catarina, 2010. p.

$1-8$.

REIS, Lyria Maria dos; RAMOS, Natália. Migração, aculturação e saúde bucal de brasileiras e brasileiros residentes em Lisboa, Portugal. Revista Ciência Plural, v. 2, n. 1, 2016, p. 56-68.

ROCHA, Cristianne Maria Famer. et al. Migração internacional e vulnerabilidade em saúde: tópicos sobre as políticas de saúde e de saúde sexual e reprodutiva em Portugal. Hygeia: Revista brasileira de geografia médica e da saúde, v. 8, n. 15, dez. 2012, p. 190-200.

ALENCAR-RODRIGUES, Roberta de; STREY, Marlene Neves; ESPINOSA, Leonor Cantera. Marcas do gênero nas migrações internacionais das mulheres. Psicologia \& Sociedade, v. 21, n. 3, 2010, p. 421-430.

RUTLAND, Adam. et al.. Os imigrantes e a imigração aos olhos dos portugueses: manifestações de preconceito e perspectivas sobre a inserção de imigrantes. Lisboa: Fundação Calouste Gulbenkian, 2012. 256 p.

SANTOS, Júlio Ricardo Quevedo; ROCHA, Aristeu Castilhos da. Ensinar história e cultura afrobrasileira: possibilidades e alternativas de práticas pedagógicas. Fronteiras, v. 18, n. 31, 2016, p. 68-98.

SILVA, Estefânia Gonçalves; NOGUEIRA, Conceição; NEVES, Sofia. Vivências de conciliação pessoal, familiar e profissional de mulheres brasileiras em Portugal. Migração, Mobilidade \& Direitos Humanos, v. 5, n. 2, 2016, p. 121-148.

SILVA, Samuel Costa da; LIMA, Ângela M. L. C.; MOTA, João P. R. Movimentos populacionais migratórios internacionais: dilemas e desafios ao estado e à sociedade. Revista Processus de Políticas Públicas e Desenvolvimento Social, v. 1, n. 2, 2019, p. 01-10.

TOPA, Joana; NEVES, Sofia; NOGUEIRA, Conceição. Imigração e saúde: a (in) acessibilidade das mulheres imigrantes aos cuidados de saúde. Saúde e Sociedade, v. 22, n. 2, 2013, p. 328-341.

TOPA, Joana; NEVES, Sofia; NOGUEIRA, Conceição. Inclusão/exclusão das mulheres imigrantes na saúde em Portugal: reflexão à luz do feminismo crítico. Revista Psico, v. 41, n. 3, 2010, p. 366-373.

VASCONCELOS, Iana dos Santos; SANTOS, Sandro Martins Almeida.. Who's in the family? reflections on kinship and mobility. REMHU: Revista Interdisciplinar da Mobilidade Humana, v. 25, n. 49,2017 , p. $249-265$.

WEBER, João Luis Almeida. et al. Imigração haitiana no Rio Grande do Sul: aspectos psicossociais, aculturação, preconceito e qualidade de vida. Psico-USF, v. 24, n. 1, 2019, p. 17385.

Recebido em: 26/04/2020

Aprovado em: 18/11/2020 